\title{
Fatal septicaemia due to Salmonella cholerae suis
}

\author{
I. S. BAILEY, G. GARRETT, AND A. NICOL \\ From Manchester Royal Infirmary and the Department of Pathology, University of Manchester
}

SYNOPSIS A fatal case of Salmonella cholerae suis septicaemia in a patient with mitral stenosis is described. At necropsy infection had become localized in an auricular thrombus.

Salmonella cholerae suis was first isolated by Salmon and Smith who named it the American hog cholera bacillus and considered it to be the cause of hog cholera. Since then, however, it has been established that hog cholera is of viral origin with $S$. cholerae suis as a secondary invader (Wilson and Miles, 1955). Human infection with this organism was first reported by Longcope (1902) who described two cases of a typhoid-like infection due to a 'paracolon' bacillus shown subsequently by Tenbroeck, $\mathrm{Li}$, and Yü (1931) to belong to the hog cholera group. Since then numerous case reports have appeared in the American literature (Saphra and Winter, 1957); in Great Britain only 10 full case reports have appeared (Table I). In all cases the clinical pattern of the infection falls into one or more of three groups: (1) A typhoid-like state or septicaemia, (2) focal manifestations outside the alimentary tract, and (3) a gastro-enteritis. The incidence of the infection is low. Of 7,779 salmonella infections of all types identified at the New York Salmonella Center between 1939 and 1955 , only $359(4.6 \%)$ were due to $S$. cholerae suis (Saphra and Winter, 1957). Out of a total of 16,260 salmonella infections notified in the Public Health Laboratory Service weekly sum- $N$ maries for England and Wales in 1958 and 1959, only $28(0 \cdot 17 \%)$ were due to $S$. cholerae suis; these? 28 cases occurred as isolated instances and were $\vec{A}$ scattered throughout the country. No case was $\frac{D}{0}$ reported in the Manchester area during these two $\mathbb{D}$ years. The following case of $S$. cholerae suis septicaemia is reported in view of its rarity, and of the $\stackrel{\mathbb{\Phi}}{-}$ unusual site at which the infection became localized. $\overrightarrow{0}$

\section{CASE REPORT}

A woman, aged 51, was admitted to the Manchester Royal Infirmary, under the care of Dr. William Brockbank, on 25 November 1959. In 1949, she was noted to have mitral 응 stenosis and auricular fibrillation and gave a previous $\varrho$ history of rheumatic fever at the age of 20 . For 10 years $\overrightarrow{\overrightarrow{0}}$ she had suffered breathlessness on exertion and for five $\exists$ years orthopnoea and occasional oedema.

On 10 November 1959, after an attack of shivering, she complained of an ache in both loins associated with frequency, dysuria, and fever. A catheter specimen of urine showed no pus cells but a scanty growth of $E$. colio was obtained on culture; this mild infection was treated 3 . successfully with sulphafurazole. On 14 November she

TABLE I

CASES OF Salmonella cholerae suis INFECTION RECORDED IN GREAT BRITAIN

Author
Nabarro et al. (1929)
Boycott and McNee (1936)
Herring and Nicholson (1939)
Guthrie (1941)
Schwabacher et al. (1943)
Laylee (1957)
Horler and Ismay (1960)
Bailey et al. (1961)

Sex Age

$\begin{array}{lr}\text { F } & 8 \mathrm{mth} \\ \text { M } & 20 \mathrm{yr} . \\ \text { F } & 35 \mathrm{yr} . \\ \text { F } & 33 \mathrm{yr} . \\ \text { M } & 7 \mathrm{mth} \\ \text { F } & 40 \mathrm{yr} . \\ \text { M } & 18 \mathrm{yr} . \\ \text { M } & 53 \mathrm{yr} . \\ \text { F } & 23 \mathrm{yr} . \\ \text { M } & 54 \mathrm{yr} . \\ \text { F } & 51 \mathrm{yr} .\end{array}$

Received for publication 24 January 1961
Sites of Recovery of Organism

At Necropsy

(Alive)

Heart blood, spleen

Auricular thrombus, meninges, spleen, gall bladder

(Alive)

Periarticular abscess, both middle ears Heart blood, spleen, liver

Spleen, lungs

(Alive)

(Alive)

Para-aortic lymph nodes

Auricular thrombus 


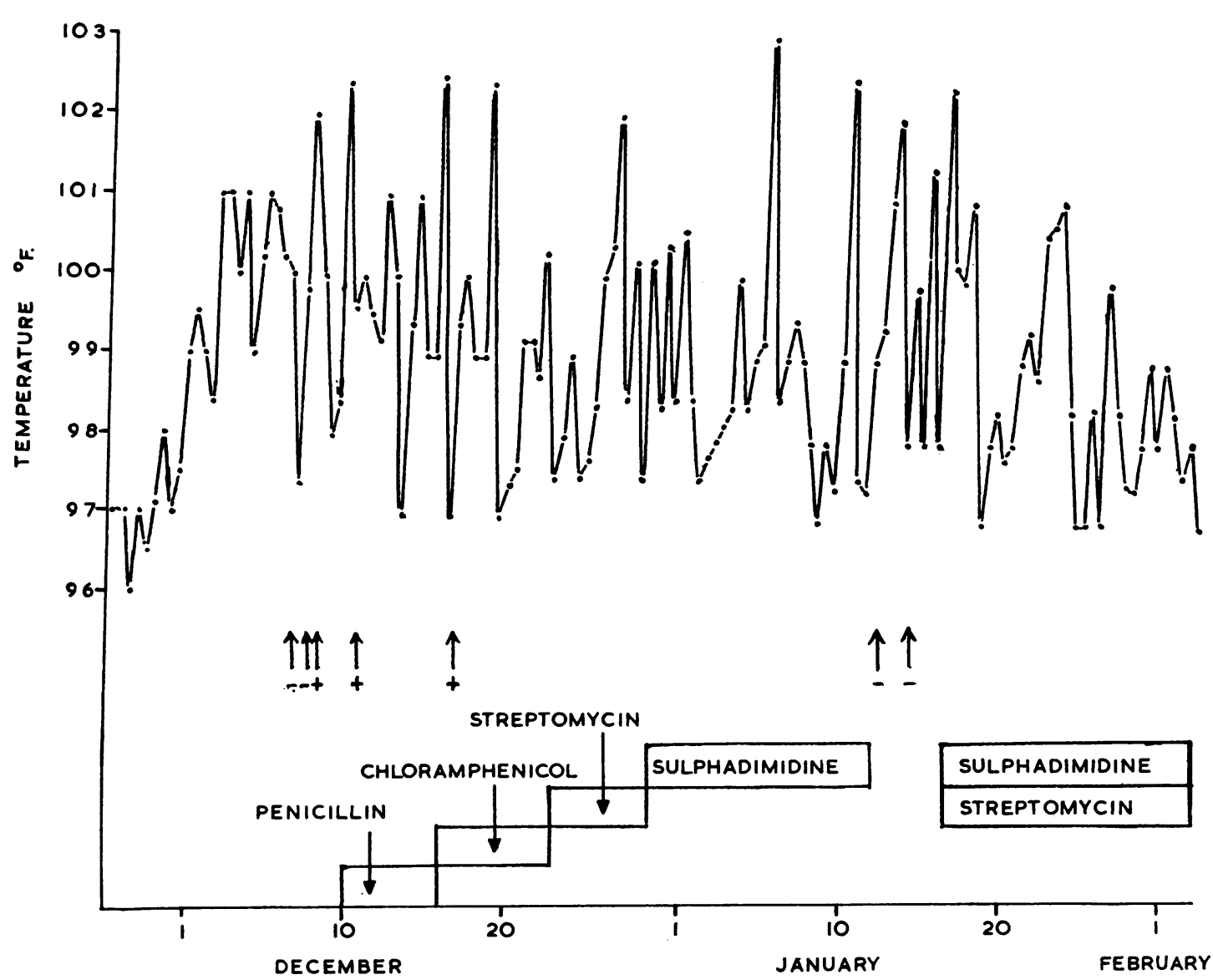

FIG. 1. Chart of temperature and treatment.

developed diarrhoea, vomiting, and abdominal colic, and these symptoms persisted for four days. She remained weak with a poor appetite and increasing thirst and because of deterioration in her condition she was admitted to hospital.

On examination she was stuporose with uraemic foetor but afebrile. The heart was enlarged, there were mitral diastolic and systolic murmurs and controlled auricular fibrillation. There was no cardiac failure. The spleen was not palpable. Her urine contained no protein or sugar.

INVESTIGATIONS Haemoglobin was 16.3 g. per $100 \mathrm{ml}$. $(110 \%)$; white blood cells 12,400 per c.mm. $(80 \%$ neutrophils); the erythrocyte sedimentation rate $6 \mathrm{~mm}$. in the first hour (Wintrobe); blood urea $188 \mathrm{mg}$. per 100 $\mathrm{ml}$. Serum electrolyte levels were sodium $122 \mathrm{mEq} . / \mathrm{l}$., potassium $3.8 \mathrm{mEq} . / 1$., chloride $70 \mathrm{mEq} . / 1$., and plasma bicarbonate $26 \mathrm{mEq}$./1.

PROGRESS AND TREATMENT Sodium and potassium supplements were given. By 3 December the serum sodium level had risen to $133 \mathrm{mEq}$./1. and the blood urea had dropped to $33 \mathrm{mg}$. per $100 \mathrm{ml}$. The patient felt better and had become alert and cheerful. On 1 December the temperature rose above normal for the first time and thereafter she ran a swinging temperature ranging between 97 and $103^{\circ}$ F. (Fig. 1). Diarrhoea did not recur and she did not at any time show any embolic phenomena. The white cell count on 4 December was 6,200; this rose to 17,400 on 7 December but thereafter fell to between 6,000 and 9,000 with isolated rises to 15,000 on 9 and 29 January 1960 and on 3 February 1960.

Blood cultures on 8, 11, and 17 December gave a growth of $S$. cholerae suis, var. kunzendorf, after nine days' incubation. Two previous blood cultures on 7 and 8 December, and two blood cultures taken after 17 December were negative. Serum collected on 10 December gave positive agglutination with composite Salmonella $H$ to a titre of $1 / 80$ but was otherwise negative. On 17 December agglutination was obtained with composite Salmonella $\mathrm{H}$ to a titre of $1 / 2,560$ and with $S$. paratyphi $C 0$ to a titre of 1/640. The organism was isolated from faeces sent for examination on 7 December but was not present on 14 December or on subsequent 
examinations. Specimens of urine remained sterile after the initial mild infection with $E$. coli had responded to treatment.

Treatment began on 10December with successive courses of penicillin, chloramphenicol, streptomycin, sulphadimidine, and then sulphadimidine with streptomycin. The fever persisted and her condition gradually deteriorated. On 2 February 1960 she had an episode of collapse with pallor, sweating, unrecordable pulse and blood pressure. She responded initially to hydrocortisone and mephentermine but despite continued steroid therapy she had two similar episodes of circulatory collapse with hypotension, and died on 7 February.

BACTERIOLOGY The organism isolated from the faeces and blood was found to have the following antigenic structure: $0-6,7 ; \mathrm{H}-\mathrm{c}: 1,5$, which is that of $S$. cholerae suis; the biochemical reactions were those of the Kunzendorf strain. The organism was sensitive to streptomycin, chloramphenicol, tetracycline, polymyxin, and sulphonamides.

\section{NECROPSY}

The relevant findings were as follows:-The heart weighed $920 \mathrm{~g}$. and was greatly increased in size mainly through enlargement of both auricles, especially the left. Both ventricles were moderately dilated with slight hypertrophy of the musculature on the right. The left auricle was solid in consistence; plaques of calcification were present in the anterior wall and the dilated cavity was occupied for the most part by a mass of laminated thrombus partially adherent to the wall, the central twothirds of which consisted of pinkish-brown pultaceous material, the appearances suggesting abscess formation. The pulmonary venous return had channelled between the auricular wall and the thrombus to reach the mitral valve which was extremely fibrosed and calcified, the orifice being reduced to the characteristic 'button-hole'

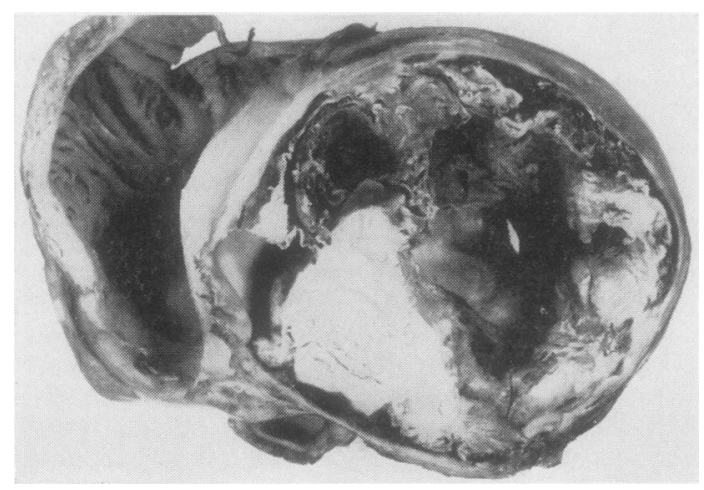

FIG. 2. Heart from above. Transverse section through both auricles to show left auricular thrombus, the central part (site of abscess) being removed to show stenotic mitral valve. Note also dilatation and trabeculation of right auricle. slit, $1.4 \mathrm{~cm}$. in length (Fig. 2). The tricuspid valve was also fibrosed and appeared to be functionally incompetent; $\overrightarrow{\bar{B}}$ the right auricle was considerably dilated and the muscle hypertrophied with prominent trabeculation of the wall. Aortic and pulmonary valves were healthy; section of the coronary arteries showed no significant lesion and there was no evidence of fibrosis of the ventricular myocardium. A small amount of clear serous fluid was present in each pleural cavity and the lower lobe of each lung was oedematous.

The liver $(1,310$ g.) showed the nutmeg mottling of $\overrightarrow{\vec{\omega}}$ chronic venous congestion.

Other organs showed no significant lesions; various sites, including spleen, kidneys, cerebral, mesenteric and ? limb arteries, were examined for evidence of embolic $\vec{A}$ phenomena but none was visible. There was no ulceration or of the intestines and Peyer's patches were not notably or hypertrophied,

Material for culture was taken from the abscess in the left auricle, blood in the right ventricle, the spleen, the gall bladder, and from the proximal, middle, and distal $c s$ parts of the lumen of the small intestine. Only one $\frac{\mathbb{D}}{8}$ positive result was obtained; this was given by the swab $\overrightarrow{\mathbb{D}}$ from the auricular abscess, the culture yielding a pure 3 growth of the organism isolated during life on three $\mathbb{\Phi}$ occasions in the patient's blood cultures.

\section{HISTOLOGY}

HEART Small masses of thrombus are present in the lumen of several of the lesser branches of the coronary circulation (Fig. 3). Probably in relation to these emboli there are microscopic areas of myocardial necrosis scattered diffusely and fairly frequently throughout the $\triangle$ walls of both ventricles (Fig. 4). The extent of the necrotic $\overrightarrow{\vec{B}}$ lesion is such that it could have contributed to the general failure of the myocardium. Similar thrombotic emboli are present also in the spleen (Fig. 5). Sections of the left auricular wall confirm the presence of calcification. Also, the myocardial fibres are considerably diminished in number and replaced by dense fibrous tissue in which there are broad strands of collagen. The adjacent thrombus shows organization of varying age at the periphery while more centrally there is a mass of $O$ necrotic material containing many neutrophil polymorphs.

LIVER Sections show the pattern of venous congestion. 을 Other organs sectioned show no significant histological abnormality. Specific staining of all sections shows no 0 Gram-negative bacilli.

The cause of death was presumed to be congestive heart failure from a severe degree of mitral stenosis and $\omega$ incompetence, the failure being aggravated terminally by $S$. cholerae suis septicaemia with infection of a leftco auricular thrombus and multiple foci of myocardial necrosis of embolic origin.

\section{DISCUSSION}

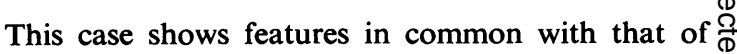
Boycott and McNee (1936). In their case mitral 


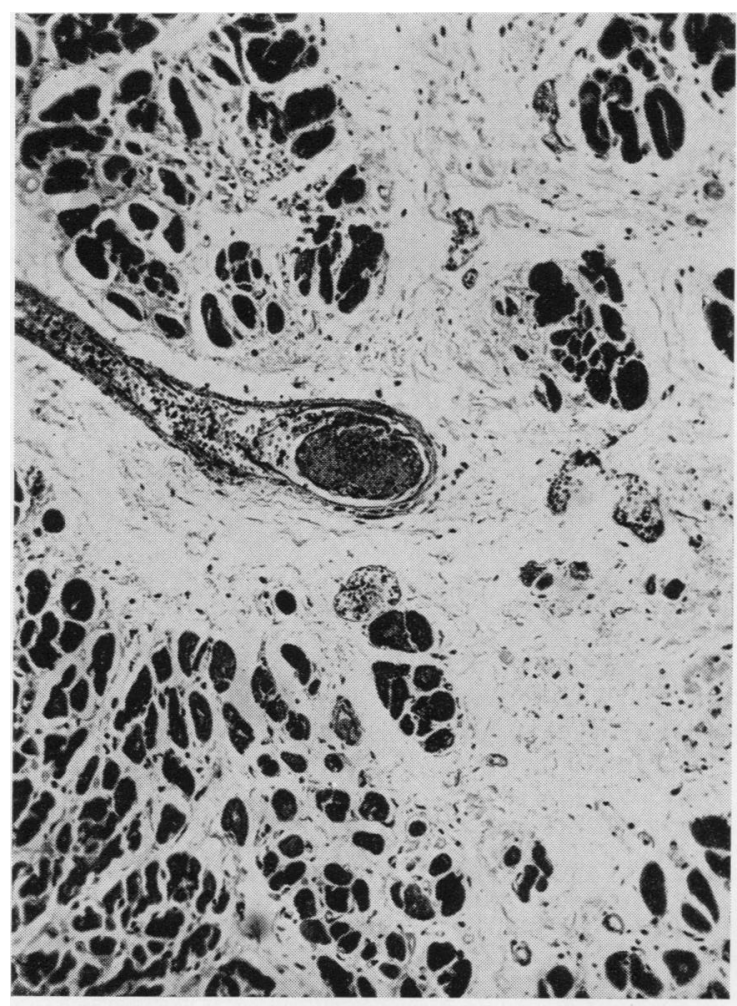

FIG. 3. Section of myocardium. Embolus in small coronary vessel. (Haematoxylin and eosin $\times 110$.)

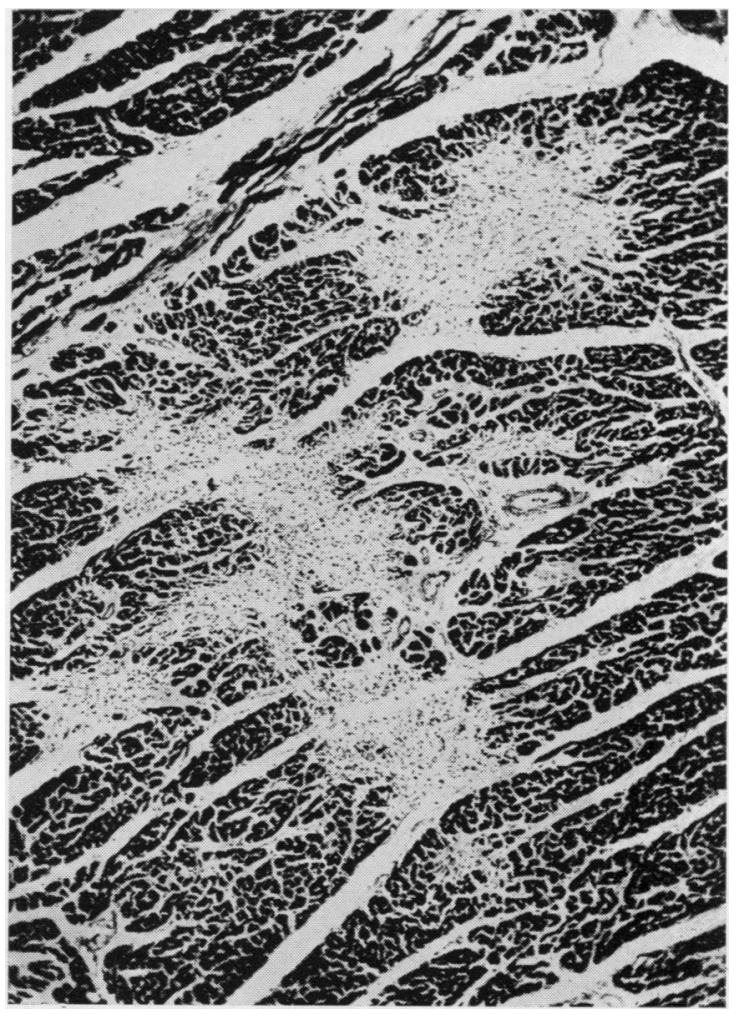

FIG. 4. Section from wall of left ventricle. Areas of necrosis of myoccrdial fibres. (Phosphotungstic acidhaematoxylin. $\times$ 50.)

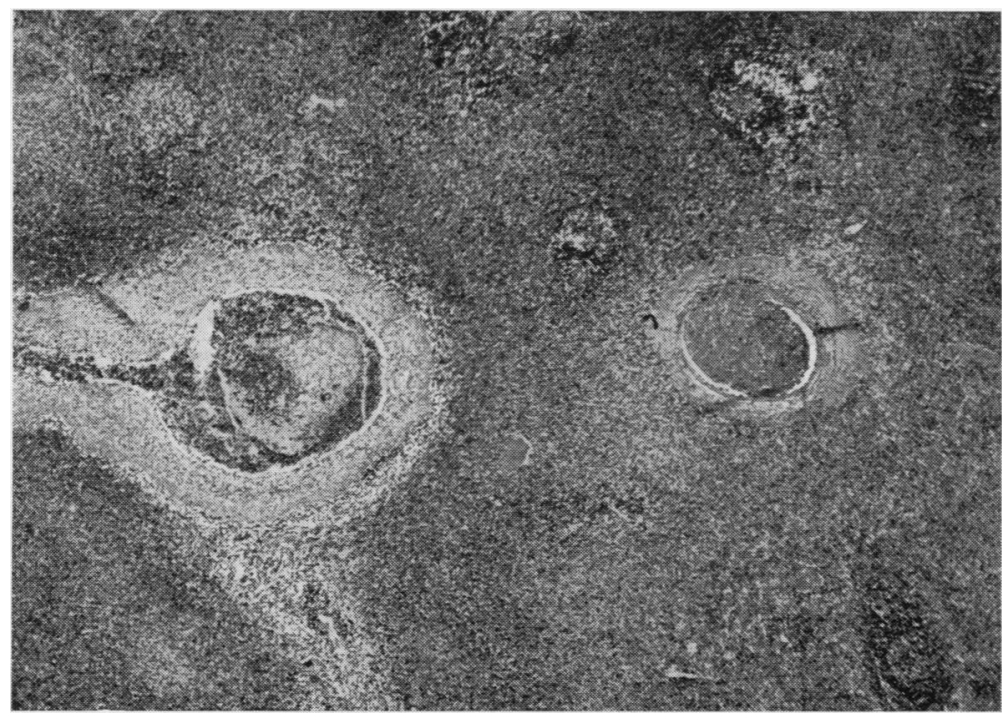

FIG. 5. Section of spleen. Two small crteries plugged by emboli. (Haemato$x y$ lin and eosin $\times 30$.) 
stenosis was present and death followed an episode of circulatory collapse. Necropsy revealed laminated thrombus filling most of the left auricle and its appendage, the organism being isolated from the thrombus. This is the only instance in which $S$. cholerae suis infection in an auricular thrombus has previously been fully substantiated. Forster (1939), in describing a patient with $S$. cholerae suis bacterial endocarditis, commented on thrombus in the right auricular appendage but gave no details of its bacteriology. A case of infected ventricular thrombus was described by Jager and Lamb (1943), who found thrombus at the site of a previous myocardial infarction and were able to culture $S$. cholerae suis from it. Infected vegetations on valve cusps have been reported more frequently; Rich and St. Mary (1956) found 24 cases in the literature and reported a further case. In our case and in that of Boycott and McNee there was no evidence of vegetation on valve cusps.

The episodes of circulatory collapse and hypotension in our case and of circulatory collapse in Boycott and McNee's case resemble the shock-like state described in patients with Gram-negative bacteraemia (Aldridge, 1960) and in other septicaemic states (Altemeier and Cole, 1956). The latter authors described 93 cases exhibiting shock in association with serious infection, and among them mentioned one case of $S$. cholerae suis septicaemia. They suggest a number of possible mechanisms, including haemoconcentration, peripheral vasodilatation, and toxic effects upon the heart, adrenals, and medullary centres. Further, Reid (1957) postulates that a generalized Schwartzman phenomenon may be implicated in some cases. It seems probable that the shock is the consequence of liberation of bacterial toxins but the precise mechanism of its action is still speculative. Spink (1960) has suggested that usual doses of steroid may be inadequate in treating shock associated with infection and claims good results from using up to $1 \mathrm{~g}$. of hydrocortisone daily for two or three days.

Mortality in $S$. cholerae suis infection is high, especially in adults. Saphra and Winter (1957) report a mortality of $20.3 \%$ in their series of 359 cases. It is unlikely that this mortality will be greatly reduced by antibiotics alone. Flippin and Eisenberg $\stackrel{\mathrm{\sigma}}{-}$ (1960) comment that for the most part treatment of $\vec{F}$ the salmonelloses with antibiotics has been unsatis- $\stackrel{P}{+}$ factory. In $S$. cholerae suis infection there is a striking tendency for localized abscesses to form and antibiotics may fail to cure a proportion of cases for $\frac{\infty}{\vec{D}}$ this reason. For instance, Fitzgerald, Snyder and $\propto$ Singleton (1959) described a patient with $S$. cholerae क suis meningitis who relapsed six times after an initial $\vec{\circ}$ clinical response to antibiotics and was cured after excision of an infected subarachnoid cyst.

The origin of the infection in the present case is not known; there were no known instances of ? infection in the family and no local cases had been $\vec{P}$ reported by the Public Health Laboratory Service. of

We wish to thank Dr. William Brockbank for permission to publish the case record, also Professor A. C. P. $\rightarrow$ Campbell and Dr. R. W. Fairbrother for helpful advice $\mathcal{D}$ and criticism. We are grateful to Dr. G. Storey for giving us access to his M.D. thesis on salmonellosis, to Dr. D. I H. Payne, of the Public Health Laboratory Service, for $\frac{3}{0}$ establishing the identity of the organism, and to Mr. N. $\stackrel{\mathbb{D}}{工}$ Mowat, F.I.M.L.T. for the photographs.

\section{REFERENCES}

Aldridge, R. T. (1960). Lancet, 2, 76.

Altemeier, W. A., and Cole, W. (1956). Ann. Surg., 143, 600.

Boycott, J., and McNee, J. W. (1936). Lancet, 2, 741.

Fitzgerald, J., Snyder, M. J., and Singleton, R. T. (1959). Ann. intern. Med., 50, 1045.

Flippin, H. F., and Eisenberg, G. M. (1960). Amer. J. med. Sci., 239, 278.

Forster, D. E. (1939). Ibid, 197, 234.

Guthrie, K. J. (1941). Arch. Dis. Childh., 16, 269.

Herring, R., and Nicholson, W. F. (1939). Lancet, 1, 1154.

Horler, A. R., and Ismay, G. (1960). Postgrad. med. J., 36, 510.

Jager, B. V., and Lamb, M. E. (1943). New Engl. J. Med., 228, 299.

Laylee, A. M. (1957). Brit. med. J., 1, 1284.

Longcope, W. T. (1902). Amer. J. med. Sci., 124, 209.

Nabarro, D., Whyte, P. B., Dyke, S. C., and Scott, W. M. (1929) Lancet, $2,868$.

Reid, J. D. (1957). N.Z. med. J., 56, 200.

Rich, M., and St. Mary, E. (1956). Ann. intern. Med., 44, 162.

Saphra, I., and Winter, J. W. (1957). New Engl. J. Med., 256, 1128.

Schwabacher, H., Taylor, J., and White, M. H. G. (1943). Brit. med. J., 2, 358.

Spink, W. W. (1960). Ann. intern. Med., 53, 1.

Tenbroeck, C., Li, C. P., and Yü, H. (1931). J. exp. Med., 53, 307.马

Wilson, G. S., and Miles, A. A. (1955). Topley and Wilson's Principles $N$ of Bacteriology and Immunity, 4 th ed., Vol. I, p. 828. Arnold, London. 